\title{
Las ideas de los docentes de ciencias con respecto al aprendizaje de sus alumnos
}

\author{
Prof. Rosario Hermano, Prof. María Inés Vique
}

\section{PresentaCión DEL PROBLEMA DE INVESTIGACIÓN}

El presente trabajo de investigación es una aproximación a las concepciones de aprendizaje que tienen los docentes de Biología, Física y Química de Ciclo Básico en relación al aprendizaje de sus alumnos. Dado que no existe una única visión del mundo, ni de la naturaleza del hombre, ni de la educación, no existe una única concepción de aprendizaje, y la concepción de aprendizaje de cada profesor condicionará su práctica docente de tal forma que implícita o explícitamente aparecerá reflejada en su accionar diario en el aula

En los Institutos de Formación Docente de nuestro país, la concepción constructivista del aprendizaje y de la enseñanza comienza a aparecer promediada la década de los ochenta. Anteriormente y de acuerdo a nuestra experiencia como egresadas del IPA, la concepción de aprendizaje hegemónica en el ámbito teórico, era la de aprendizaje por descubrimiento. Es claro que esta última se relaciona más con una estrategia de instrucción que con el proceso de aprendizaje, dando a los docentes un sesgo más didáctico que psicológico a la interpretación del aprendizaje de sus alumnos. Sin embargo, en la práctica docente dentro y fuera del Instituto de formación, convivían y se entremezclaban diversas concepciones que respondían a distintos posicionamientos teóricos.

Integrando el currículo de la Experiencia Piloto para ciclo obligatorio, en el marco de la Reforma Educativa emprendida en el país, se propone una nueva asignatura llamada Ciencias de la Naturaleza, caracterizada por una opción integradora de contenidos disciplinares de la Biología, Física y Química Las propuestas programátic as de dicha asignatura explicitan una concepción de aprendizaje entendida como aprend izaje significativo.

En la formación docente de nuestro país, no se contempla la integración de las Ciencias, ni desde los contenidos de la propia asignatura ni desde lo metodológico. Si uno de los componentes de la concepción de aprendizaje que poseen los docentes en su práctica actual, está pautado tanto por los contenidos de enseñanza como por las vivencias, recibidas durante su formación, no sería aventurado pensar que las ausencias señaladas influyeron, de alguna manera, en la concepción de aprendizaje que los mismos tienen.

Considerand o que en las nuevas propuestas programáticas, se opta por una concepción de aprendizaje donde el aprender supone el establecimiento de relaciones no arbitrarias entre el conocimiento nuevo y los conocimientos anteriores, es prioritario entonces, si la Reforma pretende cambios al nivel de la práctica docente, que los docentes conozcan y resignifiquen su propia concepción de aprendizaje.

Si a la luz de los resultados de esta investigación, encontráramos que la concepción de aprendizaje de docentes egresados de Centros de Formación Docente, difiere significativamente, de la concepción propuesta en la asignatura Ciencias de la Naturaleza, cabria preguntarse qué papel desempeñarla la concepción de aprendizaje en una futura extensión de la Experiencia Piloto.

\section{OBjetiVOS y PREGUNTAS dE INVESTIGACIÓN}

\section{Objetivo General}

Conocer si las concepciones de aprendizaje de los docentes de Biología, Química y Física de Ciclo Básico, son coincidentes o no con la concepción de aprendizaje explicitada en las propuestas programáticas de Ciencias de la Naturaleza.

\section{Objetivos Específicos}

Analizar las concepciones de aprendizaje de docentes de Biología, Química y Física de Ciclo Básico, entrevistados según un criterio fenomenográfic 0 .

Conocer las ideas implícitas que sostienen la práctica educativa.

Comparar las concepciones de aprendizaje de los docentes con la concepción de aprendizaje propuesta desde el currículo de la Experiencia Piloto. 


\section{Preguntas De InVestigación}

De todo lo antedicho surgen las siguientes preguntas que orientarán nuestra investigación: ¿Cuáles son las concepciones de aprendizaje que tienen los docentes de Biología, Química y Física de Ciclo Básico?

¿En qué aspectos difieren esas concepciones de la concepción de aprendizaje significativo?

\section{Diseño Metodolócico}

En la presente investigación trabajamos con un enfoque cualitativo, porque éste permite entender al sujeto desde su propio marco de referencia, en el entendido de que sólo pueden comprenderse y explicarse las acciones y las palabras de las personas, en relación con los significados que éstas les atribuyen a las mismas.

Por medio de la investigación cualitativa, se estudia el contexto en el que la persona actúa, dando especial importancia a la forma como conciben los conceptos. De esta manera, se busca comprender los hechos o fenómenos, partiendo del análisis de los datos obtenidos. El comprender la realidad a partir del análisis y la reflexión, nos permitirá intervenir en ella de forma más eficaz.

Dentro de éste enfoque trabajamos con el método fenomenográfico, porque éste permite categorizar conceptualmente a partir de datos de la realidad. Estas categorías son usadas como orientadoras para ag rupar diferentes "formas de entender"1 y para sistematizar el proceso de comprensión de determinados hechos. Se puede establecer un sistema de categorías de concepciones porque se supone, de acuerdo a lo que afirma Marton, que existe un "número limitado de diferentes formas de entender, /.../ siempre puedo identificar, cuatro, cinco o seis formas cualitativamente diferentes de concebir un fenómeno o problema". ${ }^{2}$ Con lo cual la fenomenografía constituye un método fundamentalmente descriptivo. Las concepciones serian las ideas y connotaciones que los hombres tienen y que orientan su acción operando más desde lo emocional que desde la lógica y lo consciente, aunque sean producto de un trabajo lógico inconsciente.

O tro supuesto básico es que la concepción que el sujeto tenga de la realidad será diferente a la realidad misma, considerando que existe una realidad objetiva y una experimentada por el sujeto. A esta realidad subjetivada es a la cual se acerca la fenomenografía, a lo que se denomina: la perspectiva de segundo orden.

Analizamos las concepciones de los docentes sobre el aprendizaje, en el supuesto de que sean éstas quienes los llevan a decidir y actuar en todos los aspectos de su práctica. Como dice Zabala: "Detrás de cualquier práctica educativa siempre hay una respuesta a "por qué enseñamos" y "cómo se aprende". ${ }^{3}$ La población investigada estuvo constituida por quince (15) profesores de Ciencias egresados del Instituto de Profesores Artigas en las asignaturas de Biología, Química y Física, cinco de cada una de ellas. Esta selección se justifica en que la asignatura Ciencias de la Naturaleza recoge contenid os de las tres disciplinas científicas.

Consideramos que la técnica más apropiada para la colecta de datos es la entrevista en profundidad, porque permite esclarecer experiencias, ideas y visiones del sujeto, comprendiendo lo que sustenta su práctica y su discurso, creando una atmósfera en la cual puede expresarse libremente. Realizamos una entrevista en profundidad y semiestructurada, ya que propusimos una serie de preguntas-guía abiertas, directas e indirectas que apuntaban a proporcionarnos distintos tipos de información. Las preguntas indirectas fueron diseñadas con el fin de estimular al entrevistado a expresar opiniones sobre diferentes aspectos de su desempeño cotidiano como docente y pretendían descubrir sus creencias más profundas, en cuanto a los vínculos docente-alumno, docente-centro educativo, características de la formación docente, profesionalidad entre otras. La pregunta directa refería a los indicadores que maneja con relación al aprendizaje de sus alumnos. Durante el transcurso de la entrevista se presentaron a los docentes, proposiciones escritas sobre tarjetas, con la consigna de expresar, fundamentando, el grado de acuerdo o desacuerdo con las mismas en términos de: acuerdo total, desacuerdo absoluto y mediano acuerdo. Las proposiciones referían a modelos teóricos sobre distintas teorías del aprendizaje.

El análisis de los datos nos permitió determinar categorías a partir del discurso, acerca de las concepciones de aprendizaje subjetivas que tienen los docentes. El mismo transcurrió en tres etapas: en la primera, se buscaron temas emergentes. En la segunda, se recurrió a determinadas pautas de análisis, que estructuran las concepciones de aprendizaje, basándonos en el análisis de las respuestas en relación con dichas pautas, se identificaron categ orías de concepciones. En la tercera etapa tomando las principales teorías relativas al aprendizaje y a la enseñanza 
como apoyo, se compararon las categorías de concepciones obtenidas en el estudio con el fin de identificar el grado de relación entre éstas y la concepción de aprendizaje significativo existente en el currículo de la Reforma en la Enseñanza Media.

En la segunda etapa se analizaron tanto las respuestas a las preguntas, como las fundamentaciones al grado de acuerdo o desacuerd o con las proposiciones. Este análisis se hizo sobre la base de las siguientes pautas papel atribuido al docente en el proceso de enseñanza y de aprendizaje, papel atribuido al alumno en el proceso de aprendizaje, factores (internos y externos al alumno) que inciden en el aprendizaje, ideas con las cuales se relaciona el proceso de aprendizaje, concepción del conocimiento, papel de la evaluación en el proceso de aprendizaje. La elección de estas pautas estuvo determinada en primer lugar por el resultado del análisis durante la primera etapa, por otra parte agregamos otras pautas basándonos en las distintas variables que influyen e intervienen en el proceso de aprendizaje. Entendimos que de esta manera enriquecíamos el análisis y proveíamos al mismo de instrumentos que ofrecieran alguna explicación a las interrogantes de investigación planteadas.

A partir del análisis propuesto anteriormente, determinamos categorías de concepciones.

\section{Categoría A:}

\section{APRENDIZAJ E COMO INCORPORACION DE CONOCIMIENTOS QUE PERMITEN SU APLICACIÓN A SITUACIONES NUEVAS}

Esta categoría está caracterizada por una comprensión del aprendizaje como proceso interno al alumno, donde la incorporación de conocimientos trae como consecuencia cambios en lo que el alumno ya conoce.

Esos cambios permitirían la aplicación de los nuevos conocimientos a situaciones novedosas. Las situaciones novedosas pueden comprender tanto la resolución de situaciones problemáticas en la situación áulica, como su aplicación al ámbito extracurricular, en el presente 0 en el futuro. 0 tros aspectos que caracterizan a esta categoría se refieren a los roles desempeñados por el docente y los alumnos en el proceso de aprendizaje. El docente desarrolla un rol orientador, guía en el proceso de aprendizaje, brindando oportunidades de adquirir conocimientos. El alumno es protagonista de su propio aprendizaje, incorpora nuevos conocimientos, modifica conceptos erróneos, relaciona contenidos, aplica conocimientos a situaciones nuevas. Lejos del rol pasivo no es considerado como un receptor de lo que el profesor brinda.

\section{Categoría B:}

\section{EL APRENDIZAJ E COMO RESULTADO ESPONTÁNEO DE ACTIVIDADES} EXPERIMENTALES

Como características de esta categoría podemos destacar: la relación del alumno con el conocimiento a través de su propia actividad, el alumno "descubre" incorporando espontáneamente. Queda suficientemente claro el rol del alumno, como quien realiza las experiencias y descubre.

\section{Categoría C:}

\section{APRENDIZAJ E COMO RESULTADO DE LA EXPLICACIÓN DEL PROFESOR}

Encontramos que las características más representativas de esta categoría tienen relación con el rol del docente y del alumno y con, cómo es concebido el conocimiento.

Con respecto al papel del docente, éste es visto como un transmisor del conocimiento el cual es fácilmente asimilable a la información. Desde este punto de vista el conocimiento es algo que parece existir fuera del sujeto que conoce, siendo el docente el depositario del mismo, quien lo transmite al alumno. Así el alumno actúa como un simple receptor de las exp licaciones del profesor, dependiendo todo el proceso de ap rendizaje de la actividad del docente. En algún caso se entendió al conocimiento como aquello que se puede memorizar y al aprendizaje como una respuesta a la explicación del docente.

En la tercera etapa, para completar nuestro análisis y una vez relevadas las categorías de concepciones de los profesores en cuanto al aprendizaje, analizamos sus relaciones con la teoría, tomando como referencia las teorías del aprendizaje más representativas, reseñadas en el marco teórico. Se intentó de esta forma, ya que el concepto estudiado ha sido explorado en el plano teórico, identificar en cada uno de los entrevistados, el grado de representatividad de las distintas teorías en sus concepciones. Para ello tuvimos en cuenta el grado de acuerdo o desacuerdo expresado en relación con las distintas proposiciones consideradas durante la entrevista. Esto sin embargo no implica considerar un absoluto paralelismo entre determinada concepción personal y 
una teoría o conjuntos de teorías en particular, dado que, como se dijo antes, la única finalidad de esta etapa es ampliar el análisis y la comprensión de la diversidad de representaciones que con respecto al aprendizaje tienen tos docentes. Una vez relevadas las relaciones entre las concepciones de los docentes y las teorías, analizamos la relación entre aquellas concepciones de aprendizaje y ta concepción propuesta desde el currículo do la Experiencia Piloto.

\section{Conclusiones}

La conclusión más destacable que pudimos extraer a partir del análisis es que las ideas de los profesores de la población estudiada, no suelen corresponder en su totalidad a una categoría de concepción pura sino a una mezcla de categorías con distintos grados de coherencia entre ellas. En la misma línea de análisis, encontramos distintos g rados de representatividad de las categorías de concepciones en cada uno de los docentes. Si bien existen docentes típicos de una categoría, otros presentan características de más de una. Consideramos que esto no se contrapone con el supuesto desde el punto de vista fenomenográfico, de que existe un número finito de concepciones posibles. Es decir que, sin desconocer el universo personal de las ideas del profesor, se reconoce el origen sociocultural del conocimiento.

Considerarnos importante destacar, además, la influencia que determinados marcos teóricos ejercen en la formulación del discurso de los entrevistados, lo que permite suponer una similar influencia en las propias concepciones. Así resulta que las características de las categorías encontradas tienen algunos puntos de contacto con las distintas concepciones teóricas descritas en la literatura.

Con respecto a la relación entre las concepciones que sobre el aprendizaje sustentan los docentes y la concepción de aprendizaje signific ativo, resulta importante destacar que algunas características de esta última aparecen representadas en alguna categoría de concepción docente, sin dejar de considerar las mezclas de éstas.

En este punto del análisis, nos vemos obligadas a reconocer que nos hemos limitado a una primera aproximación al problema mencionado en el párrafo anterior. Entendemos que llegar a comprender todos los aspectos del proceso de aprendizaje que pudieran tener incidencia en la construcción de las concepciones por parte del docente y su posterior relación con el aprendizaje significativo, exigiría la utilización de otras técnicas para la colecta de datos.

Hubiera sido importante, incluir en el diseño metodológico, la observación de las actividades del docente, tanto en el aula como en el centro educativo, e inclusive acceder a documentos manejados por él, como forma de ampliar ta perspectiva desde la cuál nos aproximamos al hecho investigado. Hubiéramos podido así, trascender del discurso a las acciones del docente, sin dejar de reconocer la importancia del análisis de aquél, si realmente queremos llegar a comprender la realidad subjetivada por la persona, es decir la perspectiva de segundo orden.

Correspondería en este punto evaluar el grado de cumplimiento de los objetivos propuestos en el proyecto de nuestra investigación. Con respecto al objetivo especifico que propone: "Analizar las concepciones de aprendizaje de docentes de Biología, Química y Física de Ciclo Básico, entrevistados según criterio fenomenográfico", creemos que ha sido cumplido de forma aceptable. Hemos logrado distinguir y caracterizar categorías diferentes de concepciones de aprendizaje en la población investigada. Con respecto, al segundo objetivo: "Conocer las ideas implícitas que sostienen la práctica educativa", creemos haber llegado a conocer las ideas al respecto que se traslucieron en el discurso del entrevistado y que nos permitieron caracterizar a las categorías. Sin embargo al igual que con el tercer objetivo. "Comparar las concepciones de aprendizaje de los docentes con la concepción de aprendizaje propuesta desde el currículo de la Experiencia Piloto", logramos un nivel de aproximación. Llegamos a "conocer" y logramos "comparar", solamente a partir de lo que tos entrevistados "dijeron hacer" o "dijeron creer", resultaría conveniente para lograr un conocimiento profundo de la temática investigada, contar con otros elementos metodológicos.

Creemos que el conocer las concepciones de tos docentes, no solo con respecto al aprendizaje, sino relativas a todos los aspectos de su profesionalidad, es especialmente importante en el marco de cualquier reforma educativa que pretenda llegar a buen fin. En relación con esto, consideramos relevante en futuras investigaciones, profundizar en el estudio de las concepciones de los profesores respecto a todos los elementos que hacen a su práctica docente, utilizando para ello variadas técnicas de recolección de datos.

${ }^{1}$ Marton, F., La Fenomenografía, Conferencia en Institutionen for Pedagogik Goterb rogs Universitet

Suecia

${ }^{2}$ lbídem

3Zabala, A., 'La práctica educativa. Cómo enseñar'. Barcelona, Graó, 1995. 